\title{
La ética dialógica, una interfaz pedagógica que aporta a la construcción de una cultura de paz en Colombia
}

\author{
Rodrigo García Jara ${ }^{1}$ \\ Jorge Enrique Ramírez Martínez ${ }^{2}$ \\ Edgar Oswaldo Pineda Martínez ${ }^{3}$
}

Recibido: 19-01-2019

Aceptado: 01 - 10-2019

\section{Resumen}

Con el acuerdo de paz firmado entre el Estado de Colombia y la guerrilla de las FARC-EP se inició formalmente un proceso de cultura de paz que, entre otros, tiene los retos de subsanar los hechos de barbarie acaecidos en el conflicto y comprometerse a no repetirlos. Este proceso de paz tiene como objetivo principal ofrecerle un futuro sin conflictos fratricidas a las nuevas generaciones $y$, por ende, una sociedad en paz. Después de este acuerdo, uno de los principales retos es recibir de nuevo en la población civil a todos los excombatientes para quienes durante muchos años la única manera de solucionar los conflictos fue la violencia. Por lo tanto, en aras de seguir construyendo la paz proponemos la ética

1. Vicerrector Académico en la Universidad Santo Tomás - Sede Villavicencio. Correo electrónico: jara551@gmail.com

Google Scholar: https://scholar.google.es/citations?user=M-iQ4kEAAAAJ\&hl=es CvLac: http://scienti.colciencias.gov.co:8081/cvlac/visualizador/generarCurriculoCv. do?cod_rh $=0001444249$

2. Coordinador de Investigación e Innovación en la Universidad Santo Tomás - Sede Villavicencio.

Correo electrónico: jorge.ramirezm@usantotomas.edu.co

ORCID: https://orcid.org/0000-0002-1171-9710

Google Scholar: https://scholar.google.es/citations?user=AJenaYYAAAAJ\&hl=es

CvLac: http://scienti.colciencias.gov.co:8081/cvlac/visualizador/generarCurriculoCv. do? cod_rh=0000674494

3. Líder del grupo de investigación Humanidades Digitales, Formación y Construcción de Paz Territorial. ABA, Universidad Santo Tomás - Sede Villavicencio.

Correo electrónico: edgarpineda@usantotomas.edu.co

Google Scholar: https://scholar.google.com/citations?user=G3DFOf4AAAAJ\&hl=en

CvLac: http://scienti.colciencias.gov.co:8081/cvlac/visualizador/generarCurriculoCv. do?cod_rh=0001584883 
dialógica como el medio más adecuado de solucionar conflictos y una herramienta vital para los procesos de reconocimiento y reincorporación ciudadana.

Palabras clave: ética dialógica, pedagogía de las emociones, cultura de paz, emociones, educación.

\section{Dialogic ethics, a pedagogical interface that contributes to the construction of a culture of peace in Colombia}

\section{Abstract}

With the peace agreement signed between the State of Colombia and the FARC-EP guerrilla, a process of a culture of peace was formally initiated, which, among others, has the challenges of rectifying the barbaric events that occurred in the conflict and committing itself not to repeat them. The main objective of this peace process is to offer a future without fratricidal conflicts to the new generations and, therefore, a peaceful society. After this agreement, one of the main challenges is to once again receive in the civilian population all the ex-combatants for whom for many years the only way to solve conflicts was violence. Therefore, in order to continue building peace, we propose dialogical ethics as the most appropriate means of solving conflicts and a vital tool for processes of citizen recognition and reincorporation.

Keywords: dialogical ethics, pedagogy of emotions, culture of peace, emotions, education. 


\section{Introducción}

La guerra que por más de cincuenta años sostuvieron el Estado colombiano y las Fuerzas Armadas Revolucionarias de Colombia de Colombia-Ejército del Pueblo (FARC-EP) Ilega a su fin el 24 de noviembre de 2016, con la firma del Acuerdo Final para la Terminación del Conflicto y la Construcción de una Paz Estable y Duradera, que da inicio a su vez a una nueva etapa en la historia de construcción del Estado colombiano como nación. En este contexto, el presente artículo pretende reflexionar sobre el proceso de paz en Colombia y presentar la ética dialógica como una intefaz apropiada para solucionar conflictos y construir un proyecto ético nacional.

Como consecuencia lógica de la suscripción del Acuerdo de Paz, la desmovilización y posterior reinserción de los excombatientes de las FARC-EP entran en un proceso largo que conlleva nuevos y grandes desafíos para el Estado y la sociedad civil, dado que los actores del conflicto deben integrarse al sistema democrático y lograr el tránsito a la vida civil, es decir, hacer parte de ese Estado contra el cual luchaban.

En tal sentido, este artículo pretende presentar la ética dialógica (comunicativa) como una intefaz pedagógica apropiada para solucionar conflictos, pero sobre todo como una herramienta adecuada para que los excombatientes ingresen a la población civil. Este artículo se fundamenta, ante todo, en el posicionamiento de la alteridad como eje central de un proyecto ético nacional, sustentada en el reconocimiento de las emociones y en aprovechar la posibilidad que dan estas para diseñar valores normativos que estén acorde con los derechos humanos.

Por supuesto, reflexionar sobre el proceso de reinserción será complejo, puesto que implica la sinergia de múltiples factores políticos, militares, de seguridad, humanitarios y socioeconómicos que deben articularse para lograr que los antiguos combatientes Ileguen de nuevo a ser ciudadanos que contribuyan al desarrollo económico y social del país. Es por esto que la ética dialógica ofrece 
unos aportes importantes para las condiciones de comunicación a través de las cuales los grupos humanos pueden elaborar códigos de valores y normas morales comunes y beneficiosas para todos los miembros (Pineda y Orozco, 2018a).

Por tal razón, el artículo presenta en primera instancia una síntesis del proceso de paz en Colombia en el periodo comprendido entre el año 2012 y el 2016, esto con el fin de contextualizar el momento histórico que implica la construcción de paz. Luego se presenta el compromiso ético de la construcción de paz desde una dinámica territorial y emocional que posibilita la construcción de paces de larga duración. Además, se exponen dos paradigmas centrales de la ética: la ética del superhombre de Nietzsche y la ética kantiana, esto con el fin de centrar la discusión en la alteridad como principio constitutivo de un Estado social de derecho; finalmente, se expone cómo la educación y la pedagogía pueden hacer real el proyecto ético de nación desde el reconocimiento de narrativas de alteridad y corporeidad.

\section{Desarrollo temático}

\section{Proceso de paz en Colombia: 2012-2016}

El 28 de agosto del año 2012, el presidente de la República de Colombia, Juan Manuel Santos, les anuncia a los colombianos el inicio de diálogos con la guerrilla de las FARC-EP para lograr un acuerdo general que conduzca a la terminación del conflicto y la construcción de una paz estable y duradera. Este anuncio correspondía a un anhelo de la paz, un sueño próspero, una utopía querida por la mayoría de los colombianos. En ocasiones anteriores, la apuesta por la construcción de la paz había sido una esperanza que se había visto rota por los intereses políticos y económicos de algunos gremios oscuros, como el narcotráfico que se beneficia con el flagelo de la guerra, por los partidos políticos que solo buscan sus intereses egoístas, por la proliferación de los grupos 
armados al margen del Estado, y finalmente por un Estado ineficiente que aún no ha logrado ganar la batalla ante la corrupción y no ha generado una presencia en la totalidad del territorio (Pineda y Orozco, 2018b).

No obstante, en las dos últimas décadas se ha desarrollado un interés nacional de los gobiernos y de los grupos vinculados históricamente a la guerra, un deseo de construir la paz. Para este nuevo proceso de paz, el Gobierno desarrolló una serie de estrategias que permitieron a todos los actores del conflicto encaminarse a un cese al fuego y de hostilidades para emprender un camino a la democracia y la paz. Este proceso evidenció no solo las deudas históricas que el Estado y los grupos armados ilegales tenían con la población civil, sino que develó profundas heridas en el campo social y político que se acrecentaron con el conflicto armado. Así mismo, se pusieron de manifiesto posibles causas que habían dado origen a las luchas revolucionarias de campesinos, indígenas y minorías étnicas que posteriormente se fueron permeando por ideologías políticas y últimamente por negocios ilícitos que acrecentaron la inequidad social en dichos territorios.

Ante esto, el proceso de paz buscó no cometer los mismos errores de procesos anteriores, $y$, junto a países internacionales garantes y colaboradores del proceso, se construyó un documento que buscaba no solo salvaguardar los acuerdos sino posibilitar un futuro digno a la población colombiana, llenando con justicia social el vacío que dejó la violencia en los territorios. Durante este proceso, el Gobierno colombiano acordó con la guerrilla de las FARC-EP unas negociaciones que inicialmente se harían paralaelas a la dinámica del enfrentamiento armado y posteriormente, con la ganancia en la confianza, con un cese bilateral al fuego. De lo anterior se entiende que un conflicto termina cuando las partes que lo promovieron negocian y acuerdan soluciones políticas consensuadas que, por lo general, se fundan en voluntades convergentes por el consentimiento político, siendo el consenso el resultado de la renegociación concretada el 24 de noviembre de 2016 (Fernández y Rey, 2017). 
Finalmente, se da el cese final al fuego y a las hostilidades y se firma el Acuerdo Final para el Fin del Conflicto, documento que contó con cinco puntos neurálgicos no solo para el fin del conflicto armado sino como pilares para la reconstrucción de un Estado social de derecho. En este orden de ideas, la política de desarrollo agrario integral, la participación política de las FARC-EP, el fin del conflicto, la solución al problema de las drogas ilícitas, las víctimas y los mecanismos de refrendación de los acuerdos fueron negociados, discutidos, acordados y establecidos a través de un documento con seis capítulos (Reforma rural integral; Apertura democrática para construir la paz; Fin del conflicto; Drogas ilícitas; Sistema Integral de Verdad, Justicia, Reparación y No Repetición; Implementación, verificación y refrendación), al que se suman la Ley de Víctimas, la Jurisdicción Especial para la Paz y la Comisión de la Verdad como procesos garantes para la construcción de paz.

\section{Sin compromiso ético no hay paces}

En Colombia las diferentes violencias asociadas a los hechos ocurridos en el marco del conflicto interno han tenido diversidad de causas y efectos; sin embargo, el daño al tejido social y a la conciencia moral puede ser el más significativo y de largo alcance. Esta erosión al tejido social ha generado desarraigo de las comunidades, así como constantes y permanentes violación y vulneración de derechos, todo esto afectando notoriamente la vida de los habitantes. Estos daños no se limitan a territorios rurales, también son evidentes en territorios barriales y comunitarios, donde los vínculos y círculos éticos de los habitantes están lastimados o no existen. Por tal razón, en situaciones de construcción de paces es pertinente ahondar en el fortalecimiento del proceso de convivencia pacífica y cultura de paces desde las emociones para una activación de la conciencia política desde la perspectiva de la ética (Pineda y Orozco, 2018c).

Lo anterior evidencia cómo en los territorios afectados por el conflicto existe una fuerte predominancia del miedo y el terror como estrategia para hacer permanente el conflicto. Entonces, se 
entiende que propiciar comportamientos desde el miedo se convierte en una práctica recurrente en territorios donde hay poca o nula presencia del Estado, lo cual lleva a que los violentos impongan un sistema normativo basado en lógicas alteradas de la ética. De esta forma, se observa que en estos territorios las emociones asociadas al terror, la humillación, la vergüenza, el asco y la repugnancia posibilitan desplazamientos, secuestros, masacres y demás formas de violencia en las que predomina la crueldad humana y que, a su vez, dan origen a tramas narrativas del mal en las cuales, equivocadamente se instalan los códigos éticos y morales de la sociedad (Quintero, Oviedo, Cuéllar y Pineda, 2017).

En ese sentido, en los territorios que han sido generadores y receptores de violencias se encuentran profundas afectaciones emocionales en sus habitantes, las cuales se manifiestan con prácticas de estigmatización hacia el otro, separándolo de la vida propia y de los proyectos de futuro que sobre un ideal comunitario se construyen; esto ha llevado a la emergencia de emociones que hacen daño en los procesos de identidad colectivos, pero, en especial, impactan las prácticas orientadas al florecimiento de la vida comunitaria desde la humillación, el odio y el desprecio hacia el otro como actor de mi proceso ético de socialización.

Ahora vemos cómo una población estigmatizada y manipulada con emociones asociadas al asco y la repugnancia, en razón de las costumbres y prácticas identitarias de los otros, considerándolas amorales, antiéticas e incivilizadas, posibilita el auge de discursos y narrativas basadas en las prácticas del horror y la guerra; estas prácticas emocionales terminan por justificar exterminios, masacres y desplazamientos. Lo anterior impone conductas basadas en la dominación y control de la población, incidiendo en los modos de relacionarse en las esferas públicas y privadas de los ciudadanos. Frente a estos estigmas y estereotipos que inciden sobre la conformación de las identidades éticas de los actores sociales, se señala la emergencia de una regulación por parte de la población acerca de su vida social y política, lo cual es posible solamente a través de una reformulación de los estatutos éticos que rigen a una sociedad. 
Por tal razón, el comprender las dinámicas éticas heterogéneas, desarrolladas a lo largo del conflicto interno y la violencia en Colombia, permite identificar una diversdad de actores, víctimas y acciones violentas acaecidas entre ciudadanos, grupos ilegales y Estado, quienes por querer imponer paradigmas éticos y morales al otro, los otros y lo otro realizaron afectaciones y humillaciones unos a otros.

De ahí que se comprenda la ética como el carácter que se forma y se adquiere a través de la virtud, para que la conducta de los seres humanos sea lo más moral y racional posible. La ética hace una reflexión crítica y argumentativa sobre las costumbres de los pueblos y de los sujetos para definir lo que es bueno, y lo que realmente le conviene a una sociedad. González (2011) sostiene que la ética "analiza las formas concretas de comportamiento moral, con el fin de definir la esencia de la moralidad, su origen y razón de ser" (p. 23). En este sentido, el proceso de paz en Colombia es un caminar moral hacia un principio ético fundamental que es la paz; es por esto que la ética como disciplina filosófica ayuda, en su reflexión, a la construcción de esta anhelada utopía.

En este sentido, la ética es el motor más importante para impulsar la paz, puesto que es ese carácter que se crea una sociedad o una persona para evitar sufrimiento y evitar injusticias y gastos innecesarios en la vida humana. La ética nos sirve para apostarle de nuevo a las grandes utopías que construyen dignidad humana. La ética sirve para construir paces justa y duraderas. Es una gran herramienta para construir civilización, objetivos comunes, actitudes para que las sociedades funcionen en el plano de la democracia, el bienestar; y en el caso colombiano, la tan anhelada paz no se podría construir sin la ayuda de la ética.

De esta forma, un proyecto ético nacional llevará a comprender que además de los daños al territorio y de las violencias desarrolladas contra los integrantes de las comunidades, la guerra ha generado profundas heridas con afectaciones en lo psicológico, afectivo y social de los individuos y sus colectivos. Entonces, se entiende cómo la guerra afecta el cuerpo y la mente de los ciuda- 
danos, haciendo mella en su bienestar emocional, quebrando los puentes comunitarios, erosionando la confianza e imposibilitando la oportunidad de reconocer en los otros una ayuda para superar la barbarie y el horror (Pineda, Orozco, Rodriguez, 2019).

Ahora bien, entre las dinámicas de despojo y humillación que trae el conflicto armado una en especial genera mayor desarraigo y estigmatización, como es el desplazamiento forzado. Esta situación producto de actos violentos es, según Truyol (1998), un desencadenante de la violación de los derechos humanos en Colombia, ya que con el desplazamiento forzado se genera una situación de vulneración permanente; es un fenómeno que persigue a las víctimas a donde quiera que ellas vayan. Así, las familias que arriban a una ciudad receptora de desplazamientos no solo sufren las afectaciones propias del hecho de la movilización y las causas de este, sino que se enfrentan a una ciudad y unos habitantes que los invisibilizan, los estigmatizan y en la mayoría de casos son revictimizados, razón por la cual son ocultados en barrios marginales donde no se satisfacen sus necesidades por parte del Estado y la sociedad civil.

De esta forma, un proyecto ético le permitiría a Colombia tener la posibilidad de la reconstrucción del sujeto en términos de la identidad, enfocándose en el reconocimiento de las características personales y sociales, con el fin de relacionarlas con una propuesta ética basada en el desarrollo de la personalidad y la superación de conflictos emocionales. Para lo anterior se remite a la narración como fuente de recolección de información, que permite identificar emociones que sean proclives para la construcción de un proyecto ético de carácter nacional.

En este sentido, es importante conocer y revisar los diferentes paradigmas éticos que se han planteado a través de la historia. En general, todos ellos han buscado la felicidad, el bien común y particular de las personas, persiguiendo, así mismo, la justicia, la felicidad y el deber ser de las acciones humanas. Es por esto que para entender la ética comunicativa como una herramienta pedagógica se analizarán algunos presupuestos éticos que se han desarrollado en la historia, por un lado, la ética del superhombre, que contradi- 
ce la ética comunicativa, y por otro, la ética kantiana, que con sus imperativos categóricos le da un cimiento fundamental a la teoría de la ética dialógica, la cual consideramos es la más acertada para comprender el proyecto ético nacional.

\section{Paradigmas en pro y en contra de la ética comunicativa}

\section{Ética del superhombre}

Esta ética la sistematizó y la planteó Friedrich Nietzsche (1844-1900). Él planteaba que el hombre ha evolucionado en sus pensamientos, lo que le llevaba a mostrar que los valores morales defendidos especialmente por la moral hebrea y cristiana son una máscara del ser humano en donde se ocultan los pensamientos e intereses egoístas de unos y la miseria de otros. Y que los valores cristianos son una forma de negar la verdadera esencia del ser humano.

Por lo tanto, para Nietzsche el verdadero hombre es aquel que es dueño de sí mismo, y divide a la humanidad en dos tipos de hombres: el débil y el poderoso, donde el poderoso es aquel capaz de crear sus propios valores y principios aislado de lo bueno y lo malo (un ser amoral o inmoral), mientras que el ser débil no es capaz de vivir por sí mismo, ya que necesita depender de una sociedad que tiene unos valores morales, una religión y unas costumbres. La ética del superhombre está muy ligada con la corriente filosófica del nihilismo, que expresa total rechazo de todos los principios religiosos y morales, afirmando que solo busca triunfar en la vida sin importar el daño que puede hacerle a otra persona (débil: que siempre trabajará en beneficio del más poderoso) (González, 2011, pp. 42-45).

La ética del superhombre está muy presente en nuestra sociedad, y en el contexto del conflicto armado en Colombia ha servido para impulsar la mayoría de las acciones violentas. En el ámbito empresarial y de los negocios, en esencia impulsa a hombres y mujeres a que manifiesten una clase de comportamiento para que 
unos pocos sometan a muchos. Es una manifestación egoísta muy actual en los sectores políticos y grandes empresarios que buscan un crecimiento económico engañando al pueblo por medio del poder de las palabras. En conclusión, el superhombre busca su placer por medio del egoísmo para alcanzar sus metas.

\section{Ética kantiana}

Este modelo ético fue propuesto por Immanuel Kant (1724-1804), quien consideraba que el fundamento principal de la moral es el deber: el valor moral solo puede radicar en la voluntad del hombre de querer hacer el bien, en la voluntad buena. "Obra siempre de tal manera que la máxima de tu voluntad pueda valer como principio de legislación universal" (González, 2011, p. 38), en esta fórmula el mismo Kant sintetiza el principio práctico del obrar moral. Esta nueva forma de pensar construye una moral autónoma y formalista en la sociedad moderna y actual. De esta manera, el hombre empieza a encontrar la perfección moral en el cumplimiento de sus deberes sin importar las consecuencias que esto tenga; lo importante es cumplir con el deber, el cual es indicado por las leyes de la sociedad. Un ejemplo de la moral de la que habla Kant es la que se le da a los niños y a los jóvenes, enfocada en el cumplimiento del deber, en la observación de los reglamentos, en el orden institucional; aunque esto parezca una educación cristiana, se está poniendo en práctica la ética kantiana.

Este modelo ético busca darle a la moral un fundamento más autónomo. Para Kant el único fundamento de la norma moral es el deber, y el criterio máximo de bondad es la buena voluntad del hombre de cumplir con el deber que indican las leyes de la sociedad. La necesidad de una acción por respeto a la ley no implica que las personas realicen deberes de mala gana, ya que, si bien este puede limitar a una persona y motivarla a actuar en contra de sus intereses, el deber aún proviene de la voluntad de desear mantener la ley moral, es decir que los incentivos racionales importan más que las propias inclinaciones de la persona. 


\section{La alteridad, un principio \\ en la construcción de la paz}

No es muy común escuchar la palabra alteridad, sin embargo, está relacionada con la empatía, que es ponerse en el lugar de otro, puesto que la alteridad es considerar y comprender al otro. Según González (2011), la alteridad se entiende como un descubrimiento de la persona ajena a nuestras vidas, por la cual podemos comprender la naturaleza de otro ser, su entorno, sus dificultades, sus pensamientos, y muchos más ámbitos que definen la personalidad del otro.

Entonces, estamos inmersos en un mundo donde el actuar del ser humano está condicionado por las limitaciones sociales. La sociedad es el lugar en donde desarrollamos el comportamiento, el lenguaje y la forma de interpretar el mundo, con el fin de vivir en armonía. La sociedad es el lugar fundamental en donde se descubre el deber de respetar al otro, de reconocer que los seres humanos necesitan vivir y estar en sociedad. La alteridad es reconocer al otro como necesario e importante para construir, dignificarnos y vivir en sociedad (Cortina, 2013). Con el fin de disminuir la malevolencia y el desorden humano que está provocando un caos en nuestra comunidad, nosotros debemos adquirir una posición ética que va de la mano con principios y valores inculcados, y que también debe apoyar nuestro pensamiento o posición frente a esta realidad. El sentido alterista apoya la aceptación de otro ser diferente al "yo" y nos permite observar, conocer los aspectos diferentes que caracterizan al otro ser (González, 2011).

En consecuencia, para poder analizar otros ámbitos externos a nuestro propio yo, se debe entender que existe más que un yo totalitario, y que se puede ampliar la visión con otros mundos, agrandar y unificar objetivos y mejorar como personas. Estar en una sociedad cambiante genera muchos alteraciones en el comportamiento humano y en la misma sociedad, es por esto que nosotros debemos elegir una postura que apoyar, y, por qué no, adquirir el sentido de alteridad que nos permite aceptar a nuestro 
prójimo tal y como es dentro de esta sociedad en la que todos debemos estar unidos y apoyarnos solidariamente (Cortina, 2009).

En este sentido, para el caso colombiano se entiende que el desarrollo de procesos de alteridad o altericidio está determinado y condicionado por las emociones vinculadas a cada uno de tales procesos, ya que estas emociones son las que posibilitan o impiden las creencias, los juicios y las valoraciones que poseen los miembros de las comunidades acerca de pautas de reconocimiento intersubjetivo en las esferas emocional, jurídica y social (Honneth, 1994). Estas emociones expresadas en tramas narrativas (saberes y prácticas) han dado lugar a dos tipos de tramas de narrativas de altericidios y una de alteridad.

Inicialmente, se encuentran las narrativas del altericidio, identificadas como retóricas de la guerra, usadas para normalizar y ejecutar acciones de crueldad y humillación. Seguidamente, se encuentra la performatividad del silencio cómplice, silencio relacionado con la indiferencia de quienes ven el conflicto como un fenómeno ajeno, y que por ello no generan oposición ni resistencia. A estas prácticas de altericidio se anteponen las llamadas poéticas de paz, tramas narrativas empleadas para hacer resistencia y re-existencia ante las barbaries de la guerra desde la alteridad (Pineda y Orozco, 2018b).

Estas tipologías de tramas narrativas sobre la alteridad y el altericidio permiten develar los significados que en la ética tiene el vivir juntos, pero en especial estas narrativas permiten identificar las violencias generadas por la implicación de las emociones, que dan lugar a nuevas violencias y a diversos modos de menosprecio y humillación. Lo anterior refleja la carga emotiva que deben tener las prácticas generadoras de alteridad, ya que estas permiten identificarnos como seres débiles y frágiles que necesitan del otro y de los otros para crear verdaderas condiciones de cultura de paz (Elías, 2012).

Estas tramas narrativas también generan un punto de análisis en el proceso de adopción de un proyecto ético nacional desde 
iniciativas de cultura ética y educación ética, categorías relacionadas con memoria, justicia, verdad, perdón y reparación, entre otras, las cuales aportarían en la construcción de trayectorias educativas en el campo de la ética, no centradas en el alcance legislativo de la Cátedra de Paz (Decreto 1038 de 2015) sino en las experiencias humanas de quienes han vivido, desde sus territorios, los hechos atroces de la guerra y las esperanzas que dan las prácticas de paz.

\section{Ética y emociones para la alteridad y la construcción de paz}

Hemos visto cómo las emociones son proclives a la construcción de paz. Estas emociones se entienden en su dimensión ética y política, por lo que contienen un carácter comunicativo y vinculante, lo cual permite reconocer a través de ellas los diferentes modos de afectación, legitimación del mal, normalización de la violencia y fragilidad de la vida pública. Sin embargo, estas emociones también permiten identificar prácticas basadas en la empatía, la alteridad, la solidaridad y la colectividad que genera el reconocerse como colectivo afectado por un hecho atroz.

En este sentido, siguiendo a Ahmed (2014), encontramos la política cultural de las emociones, las cuales permiten que haya cambios en los individuos a medida que existen o se propician cambios en lo social. Lo anterior reviste a las emociones de un carácter político en la medida en que permiten modelar procesos de larga duración con afectación en las conductas y en las prácticas morales y éticas de los ciudadanos. Así mismo, es fundamental comprender cómo estas prácticas emocionales proclives a la construcción de paz se instauran en las instituciones públicas y privadas, revalidando o rechazando prácticas de crueldad y horror (Elías, 2012). En tal sentido, la permanencia y normalización de los hechos atroces no solo dependen de la duración de la guerra, sino que mutan en situaciones de inequidad y exclusión que se ensañan con los sectores y territorios impactados por el conflicto armado. 
Entonces, las ausencias de reconocimiento o prácticas de menosprecio que en el transcurrir de la guerra van constantemente erosionando el tejido social, permitiendo situaciones de desigualdad e inequidad que afectan la calidad de vida y la dignidad humana, no dependen del final del conflicto y la entrega de armas de los actores bélicos, sino que dependen de las emociones vinculadas con el deterioro de las identidades subjetivas y colectivas por el no goce de derechos y por la exclusión social, resultando en indignidad e injuria, es decir, en agravios morales.

A partir de lo expuesto, se entiende el proceso de fortalecimiento de las emociones como una de las actividades que busca potenciar las capacidades de reconocimiento basadas en la alteridad. Por ende, la alteridad como referente de un proyecto ético nacional está basada en el enfoque de las capacidades, donde se puede demostrar que una educación ética basada en la solidaridad y el cuidado permite lograr que los ciudadanos con altas capacidades éticas y morales potencien sus capacidades de ser y hacer, centrándose en la posibilidad de decidir para elegir y actuar; es decir, estas capacidades dan cuenta de la libertad, pues no se centran en las facultades innatas individuales, sino en las capacidades internas y en las que ofrecen los entornos comunitarios; esto es lo que Nussbaum (2012) Ilamaría capacidades combinadas.

\section{Alteridad pedagógica}

El ser humano no tiene cultura desde que nace; esta se va adquiriendo con el paso del tiempo, cuando se va educando en valores, costumbres y conocimientos. La cultura se adquiere por medio de tres tipos de relaciones, como son: entre padres-hijos, educador-educando y Estado-pueblo; algunas veces estas relaciones se deben romper porque el ser humano tiene que aprender tomar sus propias decisiones y construir su propio destino. En la relación padres-hijos, los primeros quieren que sus hijos sean a imagen y semejanza suya, pero no debe ser así porque cada ser humano tiene una función diferente en la Tierra; además, se tienen gustos distintos en las vocaciones y elecciones de la vida. Se debe educar 
de tal manera que se llegue a entender que cada ser humano es diferente.

Ahora, la relación educador-educando es similar al anterior caso, porque se trata al otro como si fuera un objeto, entonces el educador debe darnos educación sobre los conocimientos adquiridos y debe trasmitir esos conocimientos para al final certificarnos que somos aptos para el sistema, pero no podemos cuestionarnos, no se nos invita a comprender, a utilizar lo que se aprende para crear. En la relación Estado-pueblo, el pueblo es quien siempre tiene las de perder porque el Gobierno es elitista, y porque quiere imponer los modelos europeos, pero no se da cuenta que debe dejar que seamos auténticos y evitar que nos impongan estilos que no nos pertenecen. El Gobierno siempre quiere que el pueblo este mal educado para poder moldearnos a su gusto. Para este tiempo necesitamos que se inicie una educación crítica y liberadora, para ser una sociedad nueva que permita ir más allá de lo que se pide y saber que no le pertenece a nadie; para eso los docentes deben organizar de manera efectiva los aprendizajes que deben enseñar a los alumnos sin discriminación alguna.

En este sentido, en Colombia los saberes y prácticas pedagógicas en ética, ciudadanía, convivencia y paz demuestran que en las situaciones de conflicto armado y ausencia de gobernabilidad se ha tendido a priorizar un tipo de formación instructiva. Podría decirse que las emergencias que resultan de la permanencia consentida de los hechos atroces llevan a establecer, en el campo de la educación, políticas, planes, proyectos, estrategias de evaluación y estudios de orden nacional e internacional acerca de las percepciones y conocimientos que poseen los estudiantes y maestros sobre sus sistemas democráticos.

De esta forma, se ha evidenciado cómo la enseñanza de la ética en Colombia se ha visto limitada por la subalternización de esta a la religión, en primera medida, y a la disciplina, en segundo término; vemos cómo desde el periodo de la Independencia hasta la década de 1930 la educación ética se concentró en la 
instrucción cívica, donde se pusieron de manifiesto las tensiones entre los discursos orientados a una retórica de guerra y los discursos religiosos que buscaban apaciguar aquellos rasgos indígenas considerados propios de seres incivilizados y sin alma. A este discurso lo acompañan relatos vinculados a emociones como la culpa, que ponen en evidencia una condición de seres imperfectos e inferiores; lo anterior llevó a la creación de políticas educativas orientadas a una formación para la paz y el sosiego (Cortina, 2000).

El proyecto educativo ético anterior se ve interrumpido por los hechos suscitados por los desmanes del 9 de abril de 1948, donde con la coyuntura de las guerras interpartidistas emerge una enseñanza de la ética orientada al fortalecimiento de las virtudes democráticas, utilizando el proyecto educativo ético como instrumento para el fomento de ideas liberales y conservadoras. Hacia los años de 1960 y 1970, la enseñanza de la ética se fusionó con la instrucción cívica, centrándose en el conocimiento memorístico del funcionamiento del Estado y de las instituciones políticas. Por ende, la enseñanza de la ética se centró en valores ciudadanos urbanos, olvidando a campesinos, indígenas y afrodescendientes del proyecto ético de nación.

Solamente hacia finales de los setenta y, más propiamente, en la década de los ochenta se evidencia un giro en la enseñanza de la ética en Colombia, entre otras razones debido a que en América Latina suceden diversas transiciones de gobiernos dictatoriales a gobiernos democráticos, lo cual posibilitó que se impulsara la formación ética desde una perspectiva democrática. Para entonces, la noción de instrucción cívica se separa de la formación ética, dejando la primera a la educación o formación democrática y la segunda a la formación ética, especialmente en la formación en derechos humanos (DD. HH.). El giro en este campo se consolidó con la Constitución Política de Colombia (1991), cuyos artículos 11 al 41 exponen los derechos fundamentales de los colombianos y se convierten en guías legítimas y jurídicamente constituidas del comportamiento legal y moral de los seres humanos ciudadanos organizados en un Estado. 
Precisamente, es en el artículo 41 donde se interpretan los DD. $\mathrm{HH}$. dentro de un marco histórico-filosófico de la ética centrada en un principio de alteridad ejemplarizada por la formación ciudadana. A partir de la Constitución Política, en los contextos educativos se da inicio a proyectos y programas de ciudadanía en los que se recogen los problemas de la tradición ética y política, así como estrategias de innovación educativa orientadas a su aprendizaje, lo que permite la complementariedad entre marcos de interpretación conceptual con prácticas ciudadanas. Esta nueva orientación situó temas fundamentales de la ética en la educación; entre estos tenemos: DD. HH., autonomía, participación política, pluralismo y diversidad.

Posteriormente, con la aparición de la Ley General de Educación (Ley 115 de 1994), se estableció el diseño de lineamientos curriculares en las áreas fundamentales (art. 78), concebidos como apoyo y orientación docente en aspectos conceptuales y metodológicos; lo anterior da paso a los Lineamientos Curriculares de Educación Ética y Valores Humanos (1998) y a los de Constitución Política y Democrática (1998). A diferencia de la anterior trayectoria, orientada por la cultura política, en esta nueva ruta pedagógica los paradigmas filosóficos entran a guiar la formación ciudadana y ética.

Es necesario precisar que durante los años comprendidos entre 1980 y 2000 se agudizaron en Colombia el conflicto armado y las violencias, propiciados por, entre otros aspectos, la expansión territorial de las guerrillas y la aparición en la esfera pública del narcotráfico y el paramilitarismo. A esto se suma la irrupción social que el narcotráfico hizo en la estructura política y en la vida moral y ética en nuestro país. No solo el Estado se debilitó con este fenómeno; las violencias se incorporaron en la vida cotidiana en todos los sectores rurales y urbanos, clases sociales, grupos etarios, instituciones, y esfera pública y privada, instaurando un ideario ético separado de la alteridad y la solidaridad y más cercano a la humillación y a la enajenación.

Ante esto, el crecimiento progresivo del mal fue abordado por el Estado con medidas como responder con más militares; sin em- 
bargo, el daño hecho en la justicia, la política, las identidades culturales y los valores éticos no fue dimensionado ni en las políticas públicas, en general, ni en las educativas en ética y ciudadanía, en particular. Se logró un impacto mínimo en asuntos referidos a conocimientos de comportamientos ciudadanos, pero no en las prácticas, emociones y actitudes éticas y ciudadanas del quehacer diario de los ciudadanos. El daño moral a la estructura social ya estaba hecho: la envidia, la humillación, el despojo, el desplazamiento y en general el altericidio están latentes en la sociedad colombiana.

Por tal razón, atendiendo al histórico momento que vive nuestro país con la implementación de los Acuerdos de Paz, encontramos una posibilidad sin igual en potencializar la Cátedra de Paz (Decreto 1038 de 2015) para la apropiación de conocimientos y capacidades basadas en la ética dialógica que aporten en la construcción de paz. Este aporte a la Cátedra de Paz desde la ética dialógica permitirá la plena vivencia de los valores ciudadanos, los derechos humanos, la participación democrática, la prevención de las violencias y la resolución pacífica de los conflictos atendiendo a criterios de equidad, pluralidad y reconocimiento de las diferencias. Para esto es de vital importancia el fomento de una ética dialógica que permita la construcción de paz territorial basada en la alteridad y la corporeidad como referentes de reconocimiento social.

\section{La ética dialógica: cotidiana e importante en la construcción de la paz}

Esta teoría ética ha sido planteada en las últimas décadas del siglo XX por Jürgen Habermas y Karl-Otto Apel en Alemania. Está desarrollada sobre la idea de que el lenguaje y la manera de utilizarlo es un medio apropiado para solucionar los conflictos y dificultades humanas. Este modelo ético intenta ofrecer una fundamentación racional de la ética, pero encarna uno de los más grandes retos a los que se puede enfrentar una persona, ya que plantea que en toda comunicación se presuponen las bases de un comportamiento justo y correcto. "La competencia comunicativa incluye todos 
los requisitos que todo acto comunicativo que aspira a ser racional debe tener en cuenta: la verdad, la libertad y la justicia" (Camps, 2013, p. 360).

Toda comunicación aspira al entendimiento. Cuando hablamos con otras personas, presumimos que nos hallamos en un espacio libre de vicios. Es por esto que los conflictos se deben solucionar con el mejor argumento. Los argumentos y el habla se deben hacer en un contexto ideal de diálogo. Esto significa una simetría en donde los dos interlocutores manifiesten sus intereses comunes: ambos argumentos deben ser escuchados y atendidos, tanto los de unos como los de los otros; por ello a esta ética se le denomina una necesidad universal.

De esta forma, "La necesidad de una ética universal nunca fue tan urgente como en nuestra era; en la era de una civilización unificada a nivel planetario por las consecuencias tecnológicas de la ciencia" (Apel, citado por González y Marquínez, 2007, p. 110). Entonces, un mundo capitalista es tal vez cuestionable la aplicación de la ética de la comunicación. Si bien como teoría, y con los puntos que expone Camps, es cierto que por naturaleza somos seres morales y tendemos a una actitud cooperativa, es decir, somos seres de sociedad, también es cierto que somos "seres egoístas" y que se vela constantemente por el bienestar propio y de los cercanos. Ahora bien, la ética comunicativa propone un común acuerdo, como sucede en el lenguaje.

El lenguaje es un sistema sujeto a reglas, reglas que pueden ser diversas y cambiantes, pero que no pueden dejar de ser compartidas, porque no tiene sentido la regla para un solo seguidor de la misma. Dicho de otra forma, en la base de la comunicación lingüística hay un acuerdo fundamental e imprescindible $y$, si ese acuerdo falta, el lenguaje deja de cumplir su función comunicativa esencial. (Camps, 2013. p. 360)

La comunidad se encargaría entonces de examinar, formular y validar las conductas, pero no se pretende desechar este tipo de 
teoría: con "la ética discursiva" (ética comunicativa) los logros que se pueden llegar a obtener como sociedad serían grandes y provechosos. Sin embargo, hay puntos y estrategias que deben ser resueltos antes para poder comenzar a construir y pasar a los hechos dicha teoría. Uno de estos puntos es la postura crítica de cada individuo. La sociedad necesita urgentemente una educación mucho más crítica, es decir, no basta solo con llenarse de información en los institutos, escuelas y universidades, se trata de saber qué hacer con esta información, y conocer que la ética consta de virtudes, las cuales se entrenan día a día como individuo con cada decisión que se toma. No se puede pretender mejorar una sociedad sin ser consciente y autocrítico, y esto se da en un constante diálogo de simetría entre los interlocutores.

En este sentido, evidenciamos que existen unas narrativas o relatos generativos del conflicto armado en Colombia, manifestadas de forma oral, escrita y performativa, que dan lugar a sostener que la guerra y la paz no son mudas, que no suceden en el interior de los sujetos, sino que se revelan a través de tramas narrativas cargadas de emociones. Por ende, la ética dialógica busca reconocer, en primer lugar, lo que sucedió y lo que hicimos en el conflicto: entender el porqué de nuestros actos y prácticas de despojo nos hará entender la afectación de estas emociones en el devenir de la vida ética y política, comprenderemos las emociones de odio, repugnancia y asco que dan lugar a justificar la guerra. En segundo lugar, la ética dialógica permitirá reconocernos en la alteridad generada por las poéticas de la paz empleadas para hacer resistencia o convocar el cese de los hechos bélicos, pues en la guerra se atenta contra la misma humanidad y es necesario vincularnos afectivamente en las esferas del amor, la solidaridad y la identidad. Finalmente, encontramos las narrativas de la indolencia expresadas en silencios (narrativas performativas), indiferencias e insensibilidad moral y política, frente a las cuales la ética dialógica permitirá que el ciudadano indolente se sensibilice con los hechos y los actores víctimas del conflicto, reconociendo la alteridad como un proyecto ético de nación. 


\section{Conclusiones}

Este entramado de narrativas abordadas desde la ética dialógica permite comprender que las tramas narrativas y las prácticas de guerra, paz e indiferencia se alimentan de y son mediadas por emociones que nutren la vida ciudadana; emociones como odio, amor, asco, repugnancia, vergüenza, entre otras, están orientadas hacia asuntos de la vida política como la ciudadanía, los valores políticos, éticos y morales, la nación, las identidades, la libertad, la pluralidad, la vulneración derechos, entre otros, generando unas prácticas de facto que responden a particularidades del conflicto armado y social.

Precisamente una ética dialógica permitirá no solo reconocer las emociones vinculadas a las prácticas y narrativas acerca de la guerra y la paz, sino comprender la complejidad de las afectaciones vividas de manera sostenida que logran dar cuenta de la simultaneidad con que han sucedido los hechos atroces y de la permanencia de estos en nuestra memoria colectiva. Con estas narrativas develatorias acerca del carácter singular del daño podemos señalar que en Colombia es imposible construir una sola narrativa del conflicto armado y social de la manera como lo propone Ricoeur (2004), pues dadas nuestras circunstancias contextuales no sería ética, jurídica y políticamente conveniente poseer una sola narrativa de lo sucedido.

En nuestro país, al contrario que las sociedades con proceso de autorregulación, se encuentra lo que Elías (2012) Ilama monopolios estables de violencia física, es decir, instituciones que están orientadas a reprimir las emociones y modelar el comportamiento de los individuos. Este es el caso de las trayectorias de guerra y conflicto armado en Colombia, las cuales han buscado la transformación de las costumbres y hábitos de los momentos de atrocidad en nuestro país, constituyendo diversos escenarios sociales que traen consigo el moldeamiento de la conducta y la sensibilidad de los individuos ante el horror, la barbarie y la guerra (Arteta, 2010). 
Entonces, el acuerdo de paz firmado entre el Estado colombiano y las Fuerzas Armadas Revolucionarias de Colombia-Ejército del Pueblo (FARC-EP) fue un primer paso para la terminación del conflicto y la construcción de una paz estable y duradera, pero para lograr este objetivo se requiere de proceso, paciencia y de interfaces adecuadas como la ética dialógica para continuar dando pasos acertado en la construcción de la paz.

Así pues, este artículo presentó la ética dialógica (comunicativa) como una interfaz pedagógica apropiada para solucionar conflictos, pero sobre todo como una herramienta sin la cual no es posible que los excombatientes ingresen a la población civil. Reflexionar sobre este proceso será siempre una terea compleja, puesto que implica la sinergia de múltiples factores políticos, militares, de seguridad, humanitarios y socioeconómicos que deben articularse para lograr que los antiguos combatientes lleguen de nuevo a ser ciudadanos que contribuyan al desarrollo económico y social del país.

\section{Referencias bibliográficas}

Ahmed, S. (2014). La política económica de las emociones. Ciudad de Mexico: Pograma Universitario de Estudios de Género de la UNAM.

Arteta, A. (2010). La virtud en la mirada: ensayo sobre la admiración moral. Valencia: Pre-Textos.

Camps, V. (2013). Breve historia de la ética. Barcelona: RBA.

Colombia, Ministerio de Educación Nacional (1.998). Constitución Política de Colombia y Democracia, Lineamientos curriculares. Bogotá: Cooperativa Magisterio.

Colombia, Ministerio de Educación Nacional (1998). Lineamientos curriculares para el área de Educación ética y valores humanos. Bogotá: Cooperativa Magisterio. 
Congreso de Colombia (8 de febrero de 1994). Ley 115 de 1994. Ley General de Educación. Diario Oficial: 41214.

Constitución Política de Colombia (1991). Bogotá: Congreso de la República.

Cortina, A. (2000). 10 palabras claves en ética. Navarra: Verbo Divino.

Cortina, A. (2009). 10 palabras claves en filosofía política. Navarra: Verbo Divino.

Cortina, A. (2013). Educación en valores y responsabilidad cívica. Bogotá: El Búho.

Elías, N. (2012). El proceso de la civilización: investigaciones sociogenéticas y psicogenéticas. Ciudad de México: Fondo de Cultura Económica.

Fernández, C. y Rey E. (2017). El acuerdo de paz entre el Gobierno de Colombia y las FARC. Bogotá: Doctrina y Ley.

González, L. J. (2011). Ética (4. a edición). Bogotá: El Búho.

González, L. J. y Marquínez, G. (2007). Valores éticos para la convivencia. Bogotá: El Búho.

Honneth, A. (1994). La lucha por el reconocimiento. Barcelona: Crítica.

Nussbaum, M. (2012). Crear capacidades: propuesta para el desarrollo humano. Barcelona: Paidós.

Pineda, E. y Orozco, P. (2018a). La formación política como humanización mediada por la experiencia estética. Revista Virtual Universidad Católica del Norte, (53), 53-68

Pineda, E. y Orozco, P. (2018b). El papel de la educación en un Estado social de derecho para la consolidación de un(as) paz(ces) sostenible(s) y duradera(s). En G. Eljach, J. A. Escobar, L. Muñoz, G. Niño (comps.), Aportes académicos para la agenda legislativa en educación (pp. 209- 
227). [Serie Documentos Estudios Legislativos n.o 5]. Recuperado de http://cael.senado.gov.co/cael/publicaciones/57-serie-5/file

Pineda, E. y Orozco, P. (2018c). Narrativas y relatos del Buen Vivir de infancias indígenas como estrategia de construcción de paz. Revista Ciudad Paz-ando, 11(1), pp. 40-50. doi: https://doi. org $/ 10.14483 / 2422278 X .12728$

Pineda, E., Orozco, P. y Rodriguez, R. (2019). Epistemologias ancestrales, tradicionales y populares de la Orinoquia colombiana. Villavicencio: Ediciones USTA.

Presidencia de la República de Colombia. (2015). Decreto 1038 de 2015. Cátedra de Paz. Diario Oficial: 49522.

Quintero, M., Oviedo, M., Cuéllar, C. y Pineda, E. (2017). Pedagogía de las emociones para la construcción de paz en territios de postconflicto. Informe proyecto 437 , Colciencias.

Ricoeur, P. (2004). La memoria, la historia, el olvido. Ciudad de México: Fondo de Cultura Económica.

Truyol, A. (1998). Historia de la filosofía del derecho y el Estado. Madrid:

Alianza.

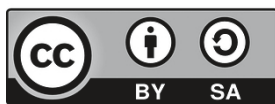

